\title{
Genomic Fingerprinting of Camelina Species Using cTBP as Molecular Marker
}

\author{
Incoronata Galasso, Antonella Manca, Luca Braglia, Elena Ponzoni, Diego Breviario \\ Istituto di Biologia e Biotecnologia Agraria (IBBA-CNR), Milan, Italy \\ Email: galasso@ibba.cnr.it
}

Received 4 March 2015; accepted 16 May 2015; published 20 May 2015

Copyright $@ 2015$ by authors and Scientific Research Publishing Inc.

This work is licensed under the Creative Commons Attribution International License (CC BY). http://creativecommons.org/licenses/by/4.0/

(c) ()

\begin{abstract}
Interest on the genus Camelina has recently increased due to the biofuel, or jet fuel, potential of the oil extracted from seeds of the cultivated species Camelina sativa (L.) Crantz. While our knowledge on $C$. sativa is constantly augmenting, only few studies have been performed on the other species of the genus, which could be a potentially useful material for the genetic improvement of $C$. sativa. The genus Camelina consists of 11 species, but only six (C. sativa, C. microcarpa, C. alyssum, $C$. rumelica, $C$. hispida and $C$. laxa) could be retrieved from germplasm banks to carry out genomic fingerprinting studies based on the use of the cTBP molecular marker. Each species, with the exception of $C$. alyssum that is proposed to be a subspecies of $C$. sativa, shows a distinct cTBP profile resulting from multiple DNA length polymorphisms present in the second intron of the members of the $\beta$-tubulin gene family. In contrast to the high level of genetic diversity detected among the six Camelina species, low variability is observed among and within the accessions of the same species, except for $C$. hispida that is characterized by an intra-accession high number of cTBP polymorphic bands. In addition, cTBP is also able to identify incorrectly classified accessions and provide information on the ploidy level of each species.
\end{abstract}

\section{Keywords}

Genetic Diversity, Polymorphism, $\beta$-Tubulin Gene Family, False Flax, Chromosome Number

\section{Introduction}

The genus Camelina belongs to the tribe Camelineae of the Brassicaceae family which contains about 338 genera and over 3700 species distributed throughout the world [1]. In this last decade, interest in this genus has increased rapidly due to the biofuel or jet fuel potential of the oil extracted from the seeds of Camelina sativa (L.) Crantz [2]-[5]. Several authors report that the biofuel produced from Camelina oil can cut greenhouse gas emis-

How to cite this paper: Galasso, I., Manca, A., Braglia, L., Ponzoni, E. and Breviario, D. (2015) Genomic Fingerprinting of Camelina Species Using cTBP as Molecular Marker. American Journal of Plant Sciences, 6, 1184-1200. 
sions (GHG) by up to 75\% compared to that of petroleum-based jet fuel [6] [7]. In addition to its use for biofuel production, a broad range of nutritional, medicinal and industrial applications of the oil have been also described [8] [9]. Camelina oil contains a high amount of unsaturated fatty acids (more than 90\%), low concentration of erucic acid and high levels of natural antioxidants (tocopherols) [10]-[13].

Recently, many studies have been undertaken on the genetic and genomic characterization of $C$. sativa. In 2006, a preliminary genetic map of C. sativa has been constructed using 157 Amplified Fragment Length Polymorphism (AFLP) markers and 3 Brassica Simple Sequence Repeats (SSRs) [14]. Since then, the level of genetic diversity present in Camelina germplasm collections has been further assessed with the use of many others dominant or codominant molecular markers such as RAPDs (Random Amplification Polymorphic DNA), AFLPs (Amplified Fragment Length Polymorphisms), h-TBP (horse Tubulin-Based Polymorphysm) and SSRs (Simple Sequence Repeats) [15]-[18]. Nearly all of them have revealed the occurrence of a limited level of genetic diversity among the different Camelina accessions and strongly support the hypothesis of a polyploid origin for the Camelina genome [14] [18]. A polyploid origin is also suggested by Hutcheon et al. [19], who study the number and the genomic organization of genes involved in the fatty acid biosynthesis pathway, and by Galasso et al. [17] who similarly analyse the $\beta$-tubulin multigene family. Recently, a genome draft of $C$. sativa has been published and the sequence analysis confirmed that Camelina is a polyploid species constituted by three genome complements [20].

While our knowledge on $C$. sativa is progressively increasing, few studies have been so far performed on the taxonomy and the genetic and genomic characterization of the other species belonging to the genus Camelina, a source of genes potentiallly useful for widening the genetic base of $C$. sativa in the effort of improving it through classical or molecular-assisted breeding. According to Warwick et al. [1], the genus Camelina consists of 11 species. However, only the following six species are currently stored in the germplasm banks of IPK (Plant Genetics and Crop Plant Research, Germany) and USDA (United Stated Department of Agricultural, USA): C. sativa, C. alyssum (Mill.) Thell., C. microcarpa Andrz. ex DC., C. rumelica Velen, C. hispida var. grandiflora (Boiss.) Hedge and C. laxa C. A. Mey. According to Plessers et al. [21] C. sativa, which is the only cultivated species, comprises three subspecies: ssp. pilosa D.C., ssp. sativa s. str. Fr. and ssp. foedita Fr. In particular, $C$. sativa ssp. pilosa is a winter type and requires vernalisation to promote stem elongation and flowering, while ssp. sativa and ssp. foetida are defined as spring types since they do not require vernalisation [21]. Presently, only $C$. sativa ssp. sativa and ssp. pilosa are stored in IPK and USDA germplasm banks while no accessions of the ssp. foetida can be found in either of the two.

Given all these premises, we have set up experiments to fingerprint the genome of all the available Camelina species, based on the use, as molecular markers, of the introns of the $\beta$-tubulin gene family [22] [23]. The technique, named TBP (tubulin-based polymorphism) or CTBP or hTBP, depending on which intron or combination of introns is used as a marker [23] [24], relies on an exon-primed intron-crossing (EPIC) PCR reaction. Several papers have previously demonstrated that any of these TBP techniques is well suitable for genotyping new or neglected species, often characterized by poor if any genomic information [17] [24] [25].

\section{Material and Methods}

\subsection{Plant Material}

Seeds of C. sativa (46 accessions), C. alyssum (3 acc.), C. microcarpa (13 acc.), C. rumelica (2 acc.), C. hispida var. grandiflora ( 1 acc.) and C. laxa (1 acc.) were kindly provided by the IPK (http://gbis.ipk-gatersleben.de/), USDA (http://www.ars-grin.gov/) and the Arche Noah (Austrian Seed Savers Association, Austria) genebanks (Table 1 and Table 2). All accessions were sown at the end of winter (10 March 2009) in order to define their life form (i.e. winter or spring form).

\subsection{DNA Extraction, cTBP PCR Amplification and Fingerprinting}

Genomic DNA was extracted from young leaf tissue of all Camelina accessions using the "GenElute Plant Genomic DNA Miniprep Kit”' (SIGMA-Aldrich) in accordance with the manufacturer's instructions. Intron2 of the $\beta$-tubulin gene family (Figure 1), chosen as the most informative molecular marker, was PCR amplified, as already described by Breviario et al. [23], using $10 \mathrm{ng}$ of template genomic DNA and the following forward and reverse oligonucleotide primers combination: TBPfin2 (5'-GARAAYGCHGAYGARTGYATG-3') and TBPrin2 


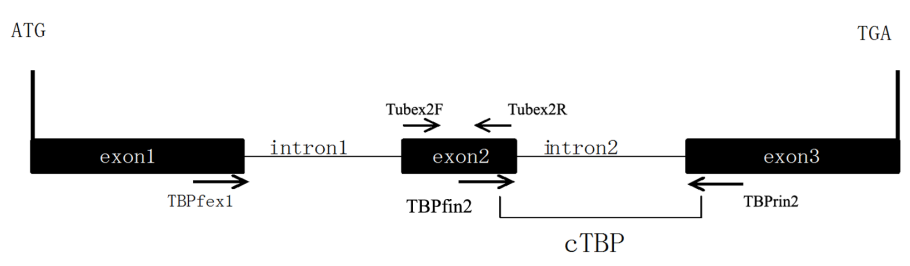

Figure 1. Schematic representation of a typical plant $\beta$-tubulin genomic locus. Arrows indicate different primers in their respective position and orientation. ATG and TGA indicate the start and stop codon, respectively. The bracket encompasses the region amplified by the cTBP method.

Table 1. List of 46 accessions of Camelina sativa used in this study with their life form, accession number, donor and country of origin.

\begin{tabular}{|c|c|c|c|c|c|}
\hline & Life form (a) & Life form (b) & Accession number & Donor & Country of origin \\
\hline C. sativa subsp. sativa & Spring type & Spring type & CAM108 & IPK $^{*}$ & Poland \\
\hline C. sativa subsp. sativa & Spring type & Spring type & CAM110 & IPK & Poland \\
\hline C. sativa subsp. sativa & Spring type & Spring type & CAM111 & IPK & URSS $^{\wedge}$ \\
\hline C. sativa subsp. sativa & Spring type & Spring type & CAM116 & IPK & Belgium \\
\hline C. sativa subsp. sativa & Spring type & Spring type & CAM123 & IPK & Poland \\
\hline C. sativa subsp. sativa & Spring type & Spring type & CAM136 & IPK & Poland \\
\hline C. sativa subsp. sativa & Spring type & Spring type & CAM137 & IPK & Denmark \\
\hline C. sativa subsp. sativa & Spring type & Spring type & CAM170 & IPK & Poland \\
\hline C. sativa subsp. sativa & Spring type & Spring type & CAM171 & IPK & Unkn \\
\hline C. sativa subsp. sativa & Spring type & Spring type & CAM173 & IPK & URSS \\
\hline C. sativa subsp. sativa & Spring type & Spring type & CAM174 & IPK & Unkn \\
\hline C. sativa subsp. sativa & Spring type & Spring type & CAM175 & IPK & Sweden \\
\hline C. sativa subsp. sativa & Spring type & Spring type & CAM187 & IPK & Spain \\
\hline C. sativa subsp. sativa & Spring type & Spring type & CAM266 & IPK & URSS \\
\hline C. sativa subsp. sativa & Spring type & Spring type & CAM268 & IPK & Bulgaria \\
\hline C. sativa subsp. sativa & Spring type & Spring type & CAM265 & IPK & Italy \\
\hline C. sativa subsp. sativa & Spring type & Spring type & CAM58 & IPK & Germany \\
\hline C. sativa subsp. sativa & Unkn & Spring type & CAM7 & IPK & Kyrgyzstan \\
\hline C. sativa subsp. sativa & Unkn & Spring type & CAM8 & IPK & URSS \\
\hline C. sativa subsp. sativa & Unkn & Spring type & CAM29 & IPK & Ukraine \\
\hline C. sativa subsp. sativa & Unkn & Spring type & CAM25 & IPK & URSS \\
\hline C. sativa subsp. sativa & Unkn & Winter type & САM31 & IPK & Poland \\
\hline C. sativa subsp. sativa & Unkn & Spring type & САM34 & IPK & URSS \\
\hline C. sativa subsp. sativa & Unkn & Spring type & САМ35 & IPK & URSS \\
\hline C. sativa subsp. sativa & Unkn & Winter type & CAM37 & IPK & URSS \\
\hline C. sativa subsp. sativa & Unkn & Spring type & САМ38 & IPK & Austria \\
\hline C. sativa subsp. sativa & Unkn & Spring type & CAM40 & IPK & Unkn \\
\hline C. sativa subsp. sativa & Winter type & Spring type & CAM172 & IPK & URSS \\
\hline C. sativa subsp. sativa & Unkn & Spring type & CAM134 & IPK & Germany \\
\hline C. sativa subsp. sativa & Spring type & Spring type & CAM120 & IPK & Poland \\
\hline C. sativa subsp. pilosa & Unkn & Spring type & САМ39 & IPK & Austria \\
\hline C. sativa subsp. pilosa & Winter type & Winter type & CAM76 & IPK & URSS \\
\hline
\end{tabular}




\section{Continued}

$\begin{array}{cccccc}\text { C. sativa subsp. pilosa } & \text { Winter type } & \text { Winter type } & \text { D9952 } & \text { IPK } & \text { Unkn } \\ \text { C. sativa subsp. pilosa } & \text { Winter type } & \text { Winter type } & \text { CAM132 } & \text { IPK } & \text { Unkn } \\ \text { C. sativa subsp. pilosa } & \text { Spring type } & \text { Spring type } & \text { CAM270 } & \text { IPK } & \text { Swiss } \\ \text { C. sativa subsp. pilosa } & \text { Unkn } & \text { Spring type } & \text { CAM180 } & \text { IPK } & \text { Germany } \\ \text { C. sativa ssp. } & \text { Spring type } & \text { Spring type } & \text { CAM269 } & \text { IPK } & \text { United kingdom } \\ \text { C. sativa ssp. } & \text { Spring type } & \text { Spring type } & \text { CAM45 } & \text { IPK } & \text { URSS } \\ \text { C. sativa ssp. } & \text { Spring type } & \text { Spring type } & \text { CAM46 } & \text { IPK } & \text { Unkn } \\ \text { C. sativa ssp. } & \text { Unkn } & \text { Winter type } & \text { PI650168 } & \text { USDA } & \text { United States } \\ \text { C. sativa ssp. } & \text { Unkn } & \text { Spring type } & \text { PI650146 } & \text { USDA } & \text { Sweden } \\ \text { C. sativa ssp. } & \text { Unkn } & \text { Spring type } & \text { PI650142 } & \text { USDA } & \text { Denmark } \\ \text { C. sativa ssp. } & \text { Unkn } & \text { Spring type } & \text { FF084 } & \text { Arche } & \text { Austria } \\ \text { C. sativa ssp. } & \text { Unkn } & \text { Spring type } & \text { FF006 } & \text { Arche } & \text { Austria } \\ \text { C. sativa ssp. } & \text { Unkn } & \text { Spring type } & \text { FF004 } & \text { Arche } & \text { Austria } \\ \text { C. sativa ssp. } & \text { Unkn } & \text { Winter type } & \text { PI650167 } & \text { USDA } & \text { Poland }\end{array}$

(a) Life form as reported in the genebanks; (b) Life form as verified in this work. Unkn= unknown life form or country of origin. * IPK, Leibniz Institute of Plant Genetics and Crop Plant Research, Gatersleben, Germany; ${ }^{ \pm}$USDA, United States Department of Agriculture, USA. ${ }^{\infty}$ Arche Noah, The Austrian Seed Savers Association, Austria; ‘URSS, Union of Soviet Republics.

\section{Table 2. List of Camelina species used in this study with their accession number, donor and country of origin.}

\begin{tabular}{|c|c|c|c|}
\hline Camelina species & $\begin{array}{c}\text { Accession } \\
\text { number }\end{array}$ & Origin & Donor \\
\hline \multirow[t]{13}{*}{ C. microcarpa } & PI650135 & France & $\mathrm{USDA}^{ \pm}$ \\
\hline & PI633191 & Montana, USA & USDA \\
\hline & PI650134 & Spain & USDA \\
\hline & PI633190 & Germany & USDA \\
\hline & PI633188 & Poland & USDA \\
\hline & PI633186 & Hungary & USDA \\
\hline & CAM6 & Germany & $\mathrm{IPK}^{*}$ \\
\hline & CAM47 & Germany & IPK \\
\hline & CAM48 & Germany & IPK \\
\hline & CAM51 & unknown & IPK \\
\hline & CAM60 & unknown & IPK \\
\hline & CAM71 & unknown & IPK \\
\hline & CAM75 & Germany & IPK \\
\hline C. alyssum subsp. alyssum & CAM176 & unknown & IPK \\
\hline C. alyssum & CAM21 & Germany & IPK \\
\hline C. alyssum & PI650132 & Germany & USDA \\
\hline C. rumelica & PI650138 & Iran & USDA \\
\hline C. rumelica & CAM244 & URSS & IPK \\
\hline C. hispida var. grandiflora & PI650133 & Turkey & USDA \\
\hline C. laxa & PI633185 & Turkey & USDA \\
\hline
\end{tabular}

${ }^{*}$ IPK Leibniz Institute of Plant Genetics and Crop Plant Research, Gatersleben, Germany. ${ }^{ \pm}$USDA United States Department of Agriculture, USA.

(5'-CRAAVCCBACCATGAARAARTG-3'). For each accession, a total of 3 up to 15 individual plants were 
analysed. Amplified products were separated on a 6\% non-denaturing acrylamide gel and bands were visualized by silver nitrate staining as reported in Breviario et al. [23]. Experiments were independently repeated two or three times, to guarantee the consistency of the genomic profile attributable to each species.

\subsection{DNA Cloning, Sequence Comparison and Phylogenetic Analysis}

Tubulin nucleotide sequences identification and isolation was carried out as reported in Galasso et al. [17]. For each species only one accession was chosen, selected as the most representative when not the only one available. Selected accessions were: C. sativa CAM134, C. microcarpa CAM47, C. rumelica CAM244, C. hispida PI650133 and C. laxa PI633185. The procedure is briefly described from here to follow. First, the $\beta$-tubulin gene family of each accession was PCR amplified from target genomic DNA using the primers combination TBPfex1 (5'AACTGGGCBAARGGNCAYTAYAC-3') and TBPrin2 (5'-CRAAVCCBACCATGAARAARTG-3). TBPfex1 anneals at the end of the first exon while TBPrin2 matches the complementary target sequence at the beginning of the third exon (Figure 1). The PCR products resulting from this amplification step were purified and cloned into the pGEM-T easy vector (Promega). About 100 clones for each accession were sequenced in both directions by Macrogen (Seul, Korea). Search on nucleotide sequence homologies was carried out consulting the National Center Biotechnology Information (NCBI) database, with the use of the BLAST algorithm (http://www.ncbi.nlm.nih.gov). A search for tandem repeat motifs and microsatellite sequences was performed using the Tandem Repeats Finder (http://tandem.bu.edu/trf/trf.html) and Sputnik (http://www.cbib.u-bordeaux2.fr/pise/sputnik.html) programs. Nucleotide sequence has been deposited in the EMBL (European Molecular Biology Laboratory) Nucleotide Database with its own specific accession number (from LN811270 to LN811335) (ESM-Table 1). Nucleotide sequences of all the investigated Camelina species were multialigned with the Clustal Omega programme (http://www.ebi.ac.uk/Tools/msa/clustalo/) using default parameters. The evolutionary genetic distance was estimated using Tamura-Nei method and a Maximum Likelihood phylogenetic tree was inferred using the Nearest-Neighbour-Interchange method using MEGA version 5 [26].

\subsection{Southern Analysis}

Genomic DNA was extracted from fresh leaf tissue, according to the method reported by Doyle and Doyle [27]. For Southern hybridisation, $5 \mu \mathrm{g}$ of C. sativa CAM134, C. alyssum CAM21, C. microcarpa CAM47, C. rumelica CAM244, C. hispida PI650133 and C. laxa PI633185 genomic DNA were digested with the restriction enzyme EcoRI, size-separated on a 1\% agarose gel and transferred onto a nylon membrane. The DNA sequence of exon2, amplified by PCR using the primers Tubex-2F: 5'-GATTCCAAGTGTGTCACTCGTTG-3' and Tubex2R: 5'-TTACAGCTAGGAGTGGTGAGCTT-3', designed on the beginning and the end of exon2, was used as probe (Figure 1). Once labelled with $\alpha-\left[{ }^{32} \mathrm{P}\right]$-dCTP, using a random primer DNA labelling kit (Fermentas, Life Sciences), the probe was used for filter hybridisation. Filters were washed in $1.5 \mathrm{mM}$ sodium citrate $\mathrm{pH}$ 7.0, 15 $\mathrm{mMNaCl}, 0.5 \% \mathrm{SDS}(0.1 \mathrm{xSSC})$, at $65^{\circ} \mathrm{C}$, before exposure to X-ray films (Biomax XAR, Kodak).

\subsection{Chromosome Counts}

Flower buds were used for chromosome preparations according to Schwarzacher and Heslop-Harrison [28]. Briefly, after a treatment with $2 \mathrm{mM}$ 8-hydroxyquinoline for $1 \mathrm{~h}$ at room temperature followed by 1 hour at $4^{\circ} \mathrm{C}$, the buds were fixed in ethanol-acetic acid $(3: 1, \mathrm{v} / \mathrm{v})$ and stored at $-20^{\circ} \mathrm{C}$ until use. Before squashing, flower buds were washed twice for $10 \mathrm{~min}$ in $1 \mathrm{x}$ enzyme buffer solution ( $0.01 \mathrm{M}$ citric acid-sodium citrate buffer, $\mathrm{pH} 4.8$ ) and then digested at $37^{\circ} \mathrm{C}$ for $45 \mathrm{~min}$ with an enzyme solution containing $1 \%(\mathrm{w} / \mathrm{v})$ cellulase (Calbiochem), $1 \%$ (w/v) Onozuka R-10 cellulase (Serva) and 20\% (v/v) pectinase (Sigma). Chromosome preparations were stained with DAPI (4', 6-diamidino-2-phenylindole) and counted under a fluorescence microscope (Axiovert 200, Zeiss) in twenty complete metaphases of somatic cells of C. rumelica, C. hispida, C. laxa and Camelina spp.

\section{Results}

\subsection{Life Form Identification}

In order to verify their life form, all Camelina accessions (Table 1 and Table 2) were sown in small plots of 1 square meter in an open field at the end of winter. Among the 46 C. sativa accessions analysed, 39 showed a 
spring life form (spring type) because they started stem elongation after 44 - 50 days from sowing. Accordingly, they have all been classified as C. sativa ssp. sativa. On the contrary, the remaining 7 accessions (CAM31, CAM37, CAM76, D9952, CAM132, PI650168 and PI650167) showed a winter life form (winter type) since they remained in a prolonged vegetative stage, producing many leaves, with no stem elongation. In fact, these accessions require a vernalization period to start stem elongation and flowering. According to Plessers et al. [21] these seven accessions can thus be classified as C. sativa ssp. pilosa. With reference to the C. sativa accessions (CAM269, CAM45, CAM46, PI650168, PI650146, PI650142, FF084, FF006, FF004 and PI650167), obtained from the germplasm banks as C. sativa ssp., they all turned out to be of the spring type with the exception of PI650168 and PI650167 that resulted winter types. Finally, all the accessions of the species C. microcarpa, C. rumelica, C. hispida and C. laxa (Table 2) exhibited a strict winter life form while C. alyssum showed both winter (CAM176) and spring types (PI650132 and CAM21).

\section{2. cTBP Fingerprinting on Camelina Species}

The cTBP method was applied to all the Camelina species and accessions listed in Table 1 and Table 2. cTBP amplifies the genomic region that contains only the second intron of the different members of the $\beta$-tubulin gene family. After PCR amplification, performed with the combination of primers TBPfin2 and TBPrin2 (Figure 1), the products were analysed on non-denaturing acrylamide gels (Figure 2 and Figure 3). The cTBP profiles detected for each species are described in more detail from here to follow.

C. sativa: forty-six accessions of different origin were genotyped using cTBP. With the exception of PI650167, all C. sativa accessions showed a very similar CTBP pattern with few polymorphic bands detected at about 500 bp, 750 bp and 800 bp (Figure 2). These polymorphisms were found in both C. sativa ssp. sativa and ssp. pilosa. Accession PI650167 showed a cTBP profile remarkably different compared to all the others $C$. sativa accessions, strongly resembling that of the majority of the accessions of $C$. microcarpa (such as PI633186 or CAM60, see Figure 3). This suggests that accession PI650167 has most likely been misclassified.

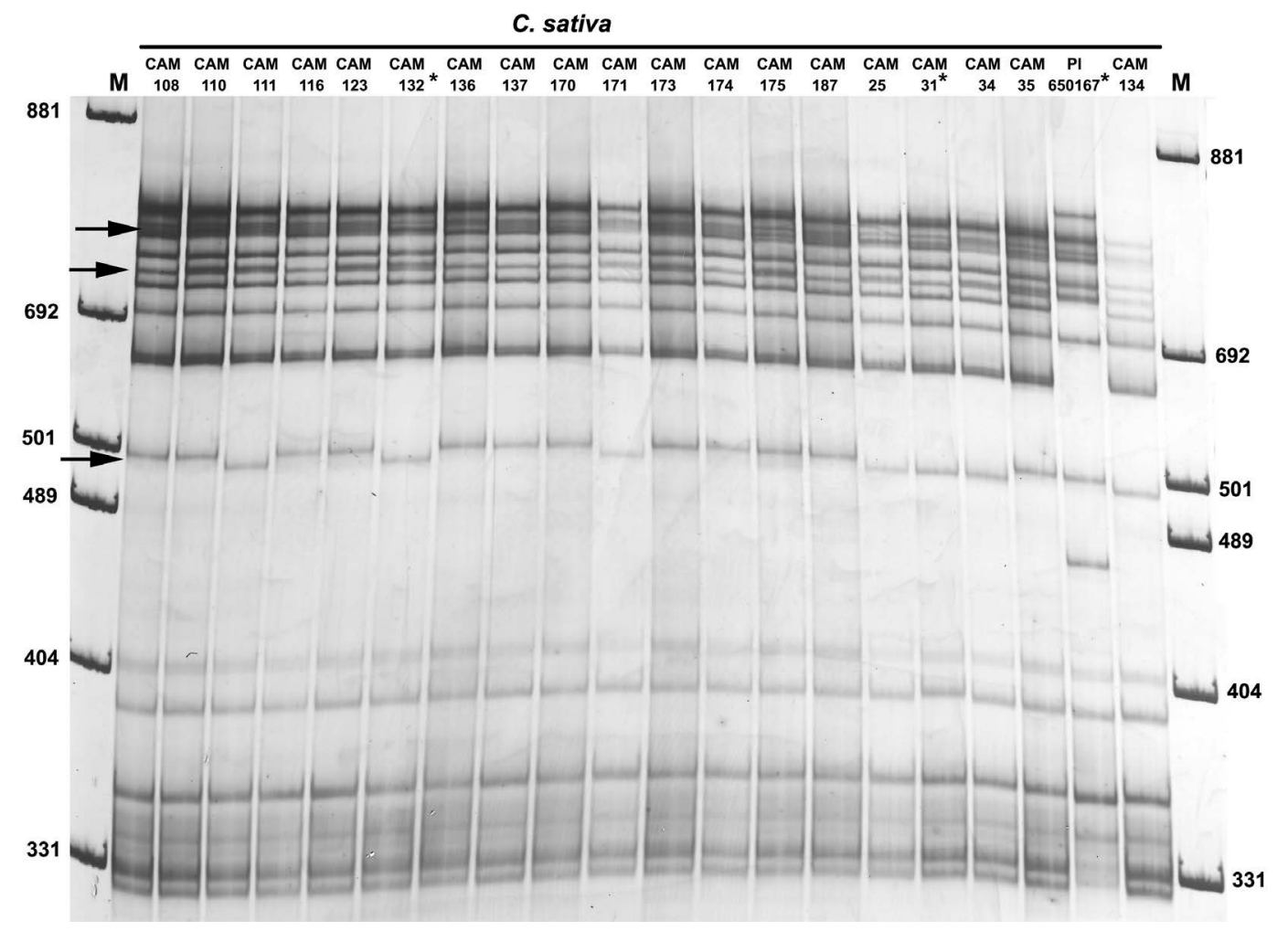

Figure 2. cTBP amplification profile of intron2 of 20 out 46 different $C$. sativa accessions. Accession numbers are reported on top of the cTBP profile. Asterisks next to the accession numbers indicate the $C$. sativa winter types. Arrows indicate polymorphic bands. $\mathrm{M}=$ Molecular marker size in bp. 


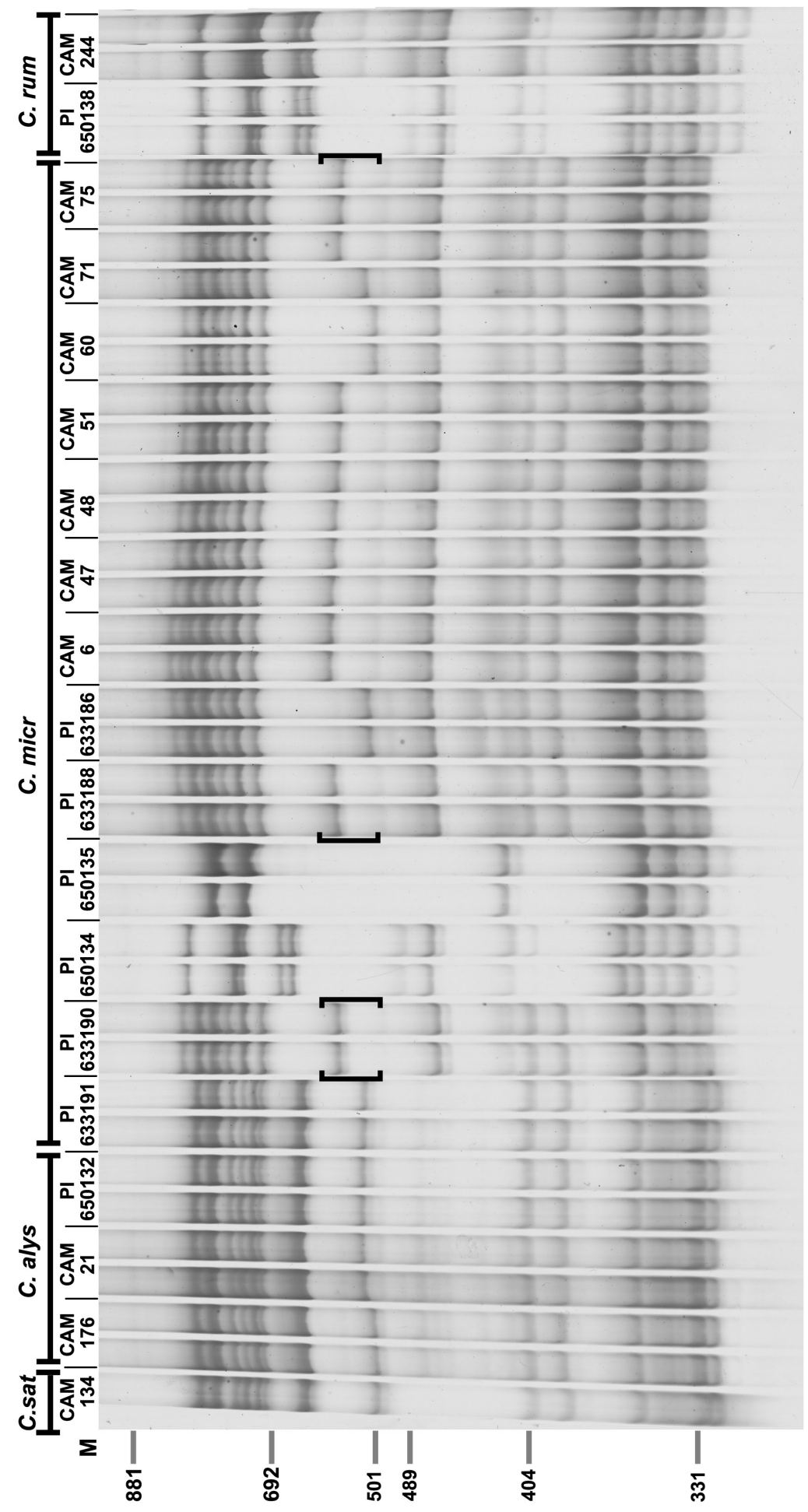

Figure 3. cTBP amplification profile of intron2 of C. sativa (C. sat), C. alyssum (C. alys), C. microcarpa (C. micr) and C. rumelica (C. rum). Accession numbers are reported on the top of the cTBP profile. For each accession, except $C$. sat CAM134 used as reference, the cTBP profile of two individuals is reported. The polymorphic bands among the $C$. microcarpa accessions are boxed. The accessions PI633191, PI650134 and PI650135 were not included between the boxes because they showed a different cTBP profile from the remaining $C$. microcarpa accessions. $\mathrm{M}=$ Molecular marker size in bp. 
C. alyssum: all three accessions showed a CTBP fingerprint substantially identical to C. sativa (Figure 3). As observed in C. sativa also the three C. alyssum accessions show a polymorphic band around 500 bp sizes. This band appears slightly higher in CAM21 and PI650132 respect to CAM176 (Figure 3).

C. microcarpa: thirteen accessions with different provenience were analysed (Table 2). According to the cTBP profiles, some of the analysed C. microcarpa accessions appear to have been misclassified. More specifically, accessions PI633191 and PI633134 revealed a cTBP profile that is, respectively, much more similar to C. sativa and C. rumelica than to C. microcarpa (Figure 3), whereas the accession PI650135 showed a unique cTBP profile, very different from any other Camelina species. Besides these three, all the remaining C. microcarpa accessions shared a very similar CTBP profile, characterized once more by the presence of a pronounced DNA polymorphism around $500 \mathrm{bp}$. The sizes of this polymorphic band is of $550 \mathrm{bp}$ in the majority of the $C$. microcarpa accessions, but PI633186, CAM60 and one individual of accession CAM71 showed a lower size fragment (Figure 3). Comparison of the cTBP profile of the majority of the C. microcarpa accessions with that of $C$. sativa and C. alyssum, reveal many bands in common. This suggests that these three species might share one common progenitor, at the least (Figure 3). Accession PI650135, of French origin (Table 2) stored at the IPK genebank as C. microcarpa, turned out to be a mixture of genetically distinguishable individuals. In fact, cTBP analysis carried out on 15 single individual plants demonstrated that only 9 showed a cTBP profile characteristic of $C$. microcarpa (data not shown), while 6 individual plants showed a distinct profile with a low number of cTBP bands, as that shown in Figure 3. Because of the distinctiveness of their profile we will refer to this group of samples as Camelina spp. In addition, the low number of cTBP amplified bands is suggestive of a diploid status.

C. rumelica: two accessions were analysed, with origin from Iran and Union of Soviet Republics (IPK genebank), respectively. Both showed a very similar cTBP pattern with no evidence for polymorphic bands (Figure 3).

C. hispida: only one accession of this species could be recovered from the genebanks. This accession resulted contaminated with seeds of other species, in particular C. microcarpa. (Figure 4(A)). Once cleaned from the
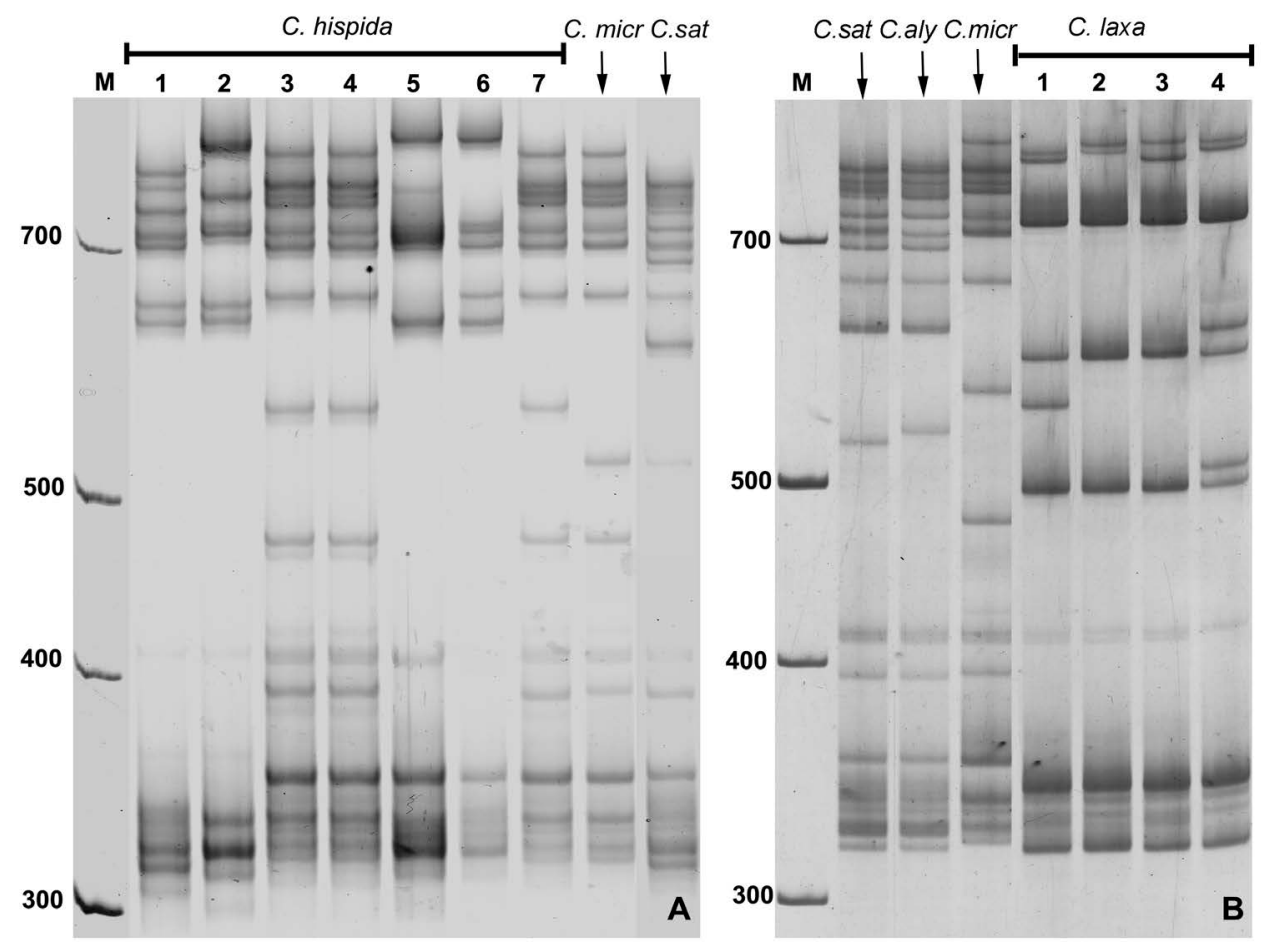

Figure 4. (A) The cTBP amplification profile of seven out of 15 individuals of $C$. hispida is compared with that of $C$. microcarpa (C. micr) and C. sativa (C. sat). Three individuals (3, 4 and 7) show a cTBP profile similar to C. microcarpa while individuals 1, 2, 5 and 6 show a high number of polymorphic bands. (B) cTBP amplification profile of 4 individuals of C. laxa showing intra-accession genetic variability. C. sativa (C. sat), C. alyssum (C. alys) and C. microcarpa (C. micr) were used for comparison. $\mathrm{M}=$ Molecular marker size in bp. 
contaminating seeds, C. hispida was nevertheless characterised by a high number of intra-accession polymorphic bands. This is in contrast with the other Camelina species which showed very few polymorphic bands between the single individuals of the same accession.

C. laxa: only one accession of this species was retrievable from the genebanks. Four single plants were analysed, showing some cTBP polymorphic bands (Figure 4(B)). Camelina laxa showed an intra-accession variability lower than $C$. hispida but higher than that of the other Camelina species.

\subsection{Sequence Comparison and Phylogenetic Analysis}

In order to isolate and sequence the complete $\beta$-tubulin gene family from each Camelina species only one accession was chosen and analysed. The accessions selected were those that showed the most representative cTBP profile of the species. In accordance, the $\beta$-tubulin gene families from C. microcarpa CAM47, C. rumelica CAM244, C. hispida PI650133 (individual number 2), C. Laxa PI6331858 (individual number 2) and a sample of Camelina spp., were PCR amplified and cloned. Nucleotide sequences of the C. sativa (CAM134) $\beta$-tubulin gene family, already available at the EMBL Database [17] were retrieved for sequence comparison and phylogenetic analysis. By using the forward TBPfex1 and the reverse TBPrin2 primers, located at the end of the first exon and at the beginning of the third exon (Figure 1) respectively, the following numbers of partial $\beta$-tubulin gene sequences were isolated from the different Camelina species: 19 from genomic DNA of C. microcarpa (CmTUB1..CmTUB19), 15 from C. rumelica (CrTUB1..CrTUB15), 12 from C. hispida (ChTUB1..ChTUB12), 11 from C. laxa (ClTUB1..ClTUB11) and 9 from Camelina spp. (CameTUB1..CameTUB9). As predicted, each of the camelina $\beta$-tubulin nucleotide sequence contained $97 \mathrm{bp}$ of the coding exon1 (partial), $270 \mathrm{bp}$ of exon 2 (complete) and 147 bp of exon3 (partial) together with the two full-length introns, 1 and 2 (ESM-Table 1). Intron length varied in all the $\beta$-tubulin isotypes of the Camelina species. The shortest ( $80 \mathrm{bp)}$ ) and the longest (936 bp) intron1 nucleotide sequence were both found in Camelina spp. (CameTUB1 and CameTUB9, respectively), whereas the shortest (82 bp) and longest (592 bp) intron2 sequences were detected in C. laxa (ClTUB3) and C. hispida (ChTUB12), respectively (ESM-Table 1). A search for tandem repeat motifs and microsatellite sequences revealed the presence in all species, with the exception of $C$. laxa, of one direct head-to-tail tandem repeat located in either the intron1 or the intron2 of some $\beta$-tubulin isotypes. Camelina microcarpa is the only species that showed the presence of one tandem repeat motif in both introns (CmTUB19). The tandem repeat located in intron2 was the longest detected (189 bp) (ESM-Table 1). Microsatellites such as trinucleotides $(\mathrm{CTT})_{6}$ and $(\mathrm{CTT})_{7}$ and dinucleotide stretches $(\mathrm{TA})_{5}$ and $(\mathrm{TA})_{6}$ were detected in introns 1 and 2, respectively. Compound microsatellites (TA $)_{5}(\mathrm{TC})_{3}$ and $(\mathrm{TA})_{7}(\mathrm{TC})_{3}$ were observed only in intron1 of Camelina spp. CameTUB9 and C. laxa ClTUB11, respectively. The multialigned nucleotide sequences of all the camelina and Arabidopsis thaliana $\beta$-tubulins were used to infer a Maximum Likelihood phylogenetic tree. As shown in Figure 5, the 95 different $\beta$-tubulin genes (86 from Camelina and 9 from A. thaliana) are grouped in two main clusters (I and II) which are further subdivided in sub-clusters (A, B, C and D). With the exception of the sub-cluster D, all the others are further subdivided in two groups (A1-A2; B1-B2; C1-C2). The phylogenetic tree spreads the analysed sequences throughout the clusters, sub-clusters and groups without distinction between Camelina species and A. thaliana. The only exception is represented by group C2 that contains only $\beta$-tubulins from Camelina species (Figure 5). Furthermore, each group includes at least one $\beta$-tubulin sequence per analysed species, except B1 that do not contain any $\beta$-tubulin of $C$. hispida and C. microcarpa.

\subsection{Southern Hybridization Analysis}

To obtain additional information on the genomic organization and the number of the $\beta$-tubulin genes present in the different Camelina species, we performed a Southern blot analysis on the EcoRI restricted genomic DNA of C. sativa, C. alyssum, C. microcarpa, C. rumelica, C. hispida, C. laxa and Camelina spp. A radioactively-labelled exon2 fragment was used as a probe. EcoRI endonuclease was chosen since no restriction sites for this enzyme are present in any of the exon2 sequences of all $\beta$-tubulins. This implies that each of the detected hybridization fragments should correspond to one gene. As shown in Figure 6 the number of hybridization bands is higher in C. sativa, C. alyssum, C. microcarpa and C. rumelica compared to that of C. hispida, C. laxa and Camelina spp. This is in agreement with the number of the isolated $\beta$-tubulin genes that was lower in C. hispida, C. laxa and Camelina spp. than in the other species. As already observed comparing the cTBP profile of $C$. sativa and $C$. alyssum (see Figure 3) also the Southern blot hybridization showed very few differences between these two species (Figure 6). 


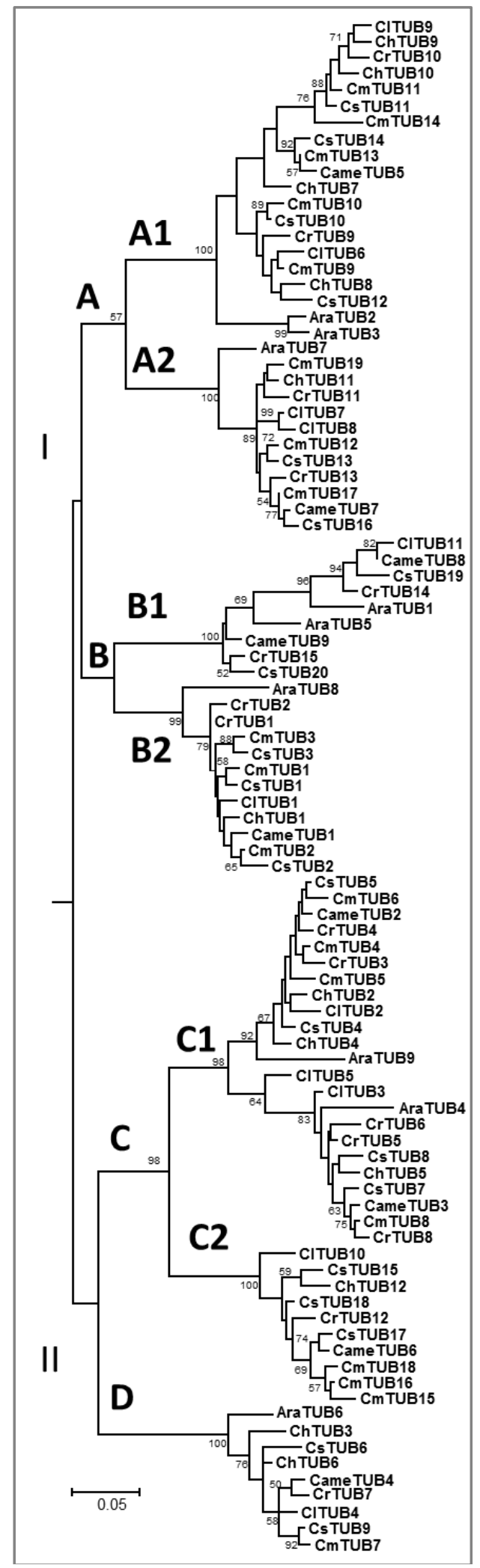

Figure 5. Phylogenetic tree constructed using MEGA software. Abbreviation CsTUB, CmTUB, CrTUB, ChTUB, Came TUB, CITUB and AraTUB indicate the Camelina and the A. thaliana $\beta$-tubulin genes, respectively. On each node the bootstrap values out of 1000 replicates are indicated. The scale bar of genetic distance is shown at the bottom. 


\section{C. sat C. alys C. micr C. rum C. his Came C. laxa}

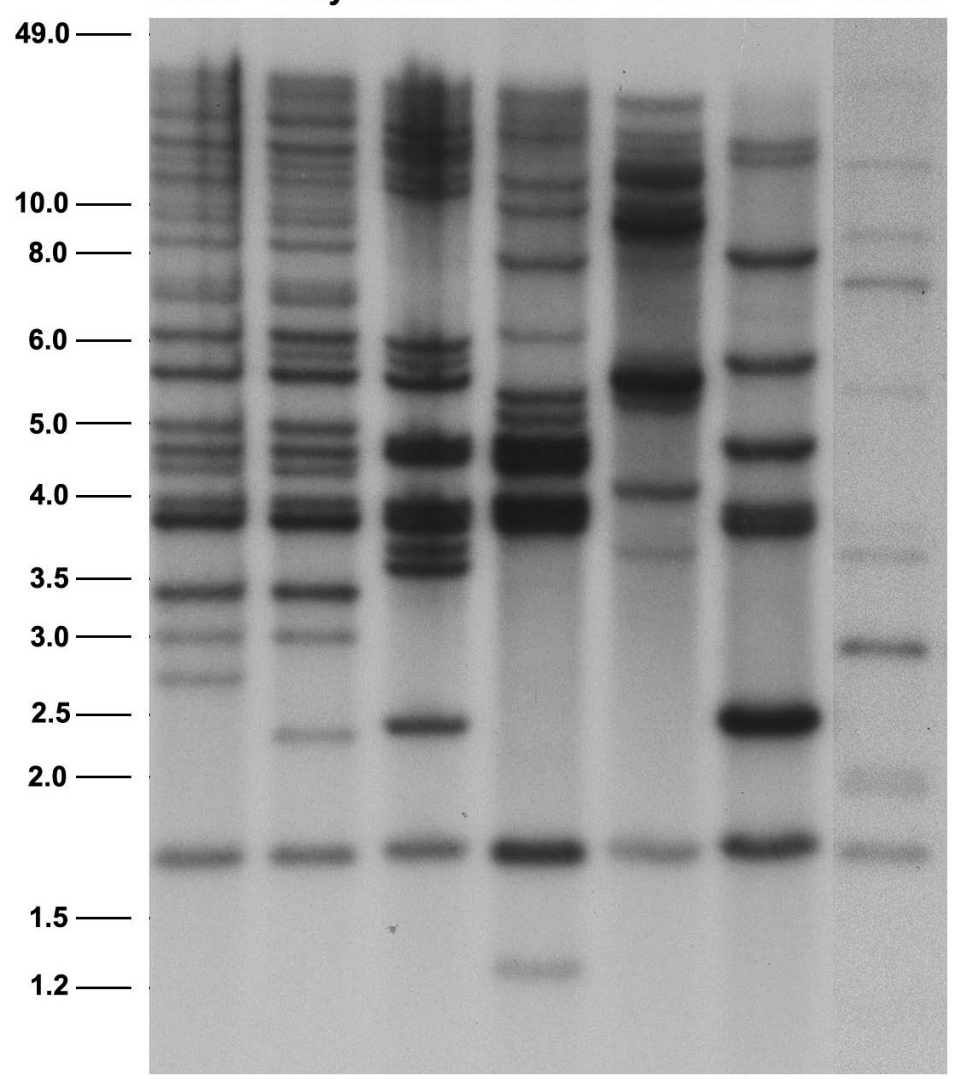

Figure 6. Southern blot analysis of genomic DNA extracted from C. sativa (C. sat), C. alyssum (C. alys), C. microcarpa (C. micr), C. rumelica (C. rum), C. hispida (C. his), Camelina spp. (Came) and C. laxa. Genomic DNAs were digested with EcoRI and probed with an exon2 fragment labelled with $\alpha$-[32P]-dCTP. Molecular size markers are indicated in kbp.

\subsection{Chromosome Number Counting}

The chromosome number resulted $2 \mathrm{n}=14$ in C. hispida and $2 \mathrm{n}=12$ in C. laxa and Camelina spp. (Figure 7) suggesting a diploid status of these three species respect to C. sativa, C. alyssum and C. microcarpa, that are all polyploids with a chromosome number $2 n=40$ [14] [29], and to C. rumelica characterized by a chromosome number $2 \mathrm{n}=26$ (Figure 7).

\section{Discussion}

The results presented here demonstrate that all Camelina species, with the exception of C. alyssum, can be easily distinguished at genomic level by using the cTBP method. In fact the multiple length polymorphism of $\beta$-tubulin intron2 gives rise to amplification profiles which resulted highly specific for each of the analysed species (see Figure 2 and Figure 3). With regard to C. alyssum, the results that we have obtained with both cTBP fingerprinting and Southern blot analysis, question its proposed classification as an independent species [29] suggesting that it may instead be better categorized as a subspecies of $C$. sativa because of the strong resemblance of their reciprocal profiles (Figure 3 and Figure 6).

The cTBP fingerprinting observed among the different accessions belonging to the same species indicates a high degree of internal genetic similarity. This result is consistent with most of the molecular studies carried out on cultivated C. sativa done with the use of different markers such as AFLP, RAPD and SSR [15] [16] [18]. In addition, no difference was substantially detected between the CTBP profiles of the two subspecies $C$. sativa ssp. pilosa (winter type) and ssp. sativa (spring type), while the consistency of the cTBP banding pattern observed across 46 different $C$. sativa accessions, collected from different countries, suggests that the PI650167 accession, characterized by a significantly different cTBP profile much more similar to C. microcarpa, has been probably 

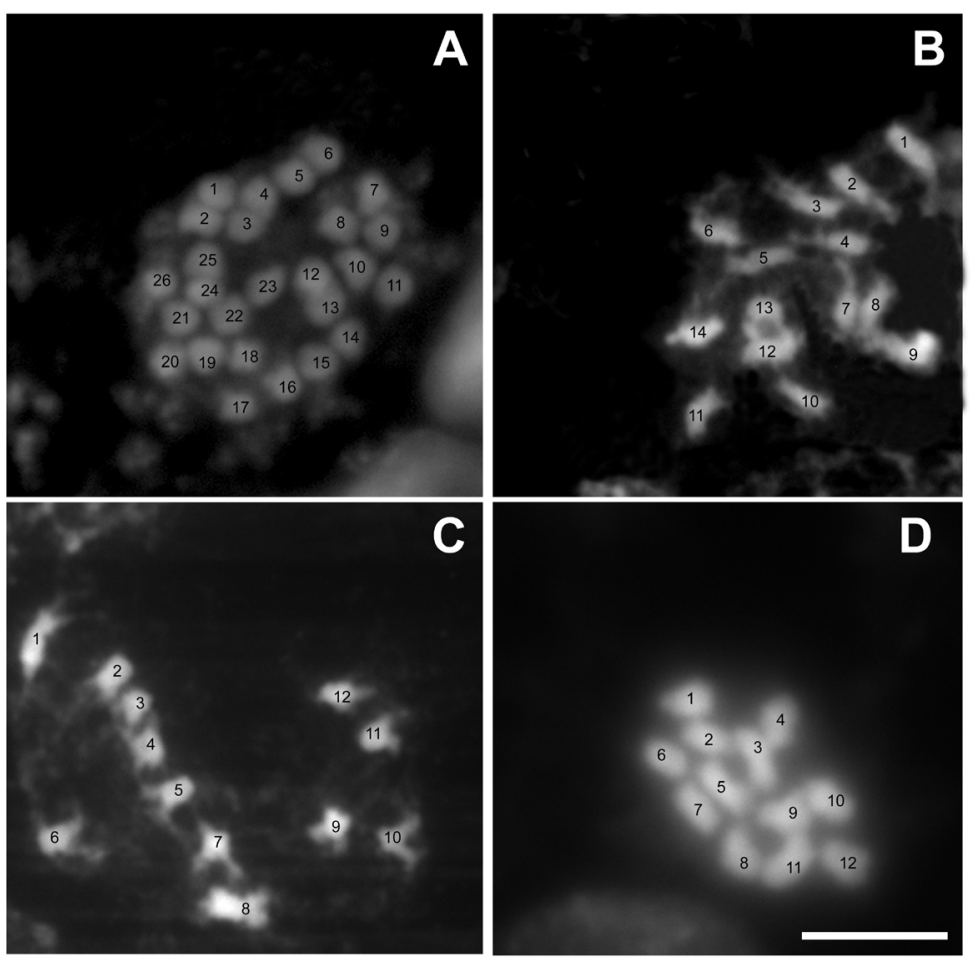

Figure 7. (A) C. rumelica; (B) C. hispida; (C) Camelina spp. and (D) C. laxa chromosomes stained with DAPI. Bar $=5 \mu \mathrm{m}$.

misclassified (Figure 2 and Figure 3).

In contrast to all the other Camelina species, which showed almost no polymorphisms among individuals of the same accession, C. hispida presented a high degree of internal polymorphism (see Figure 4(A)). At least four different CTBP profiles were detected with very few bands in common. This unexpected finding is likely to result from cross-pollination of $C$. hispida with other Camelina species since we found no evidence of contamination, i.e. all four individuals showed a very similar morphology when grown in plots until flowering stage (data not shown). As seen for C. sativa, a high number of cTBP amplified bands was detected for C. microcarpa and C. alyssum suggesting a large size of the $\beta$-tubulin gene family, which is confirmed, for both C. sativa and $C$. microcarpa, by the number of the isolated $\beta$-tubulin genes and the number of hybridizing bands in the Southern blot analysis. The number of the cTBP bands in C. rumelica and C. hispida was lower. In Camelina spp. only 9 hybridization bands were detected by Southern analysis, a number that perfectly matches that of the identified $\beta$-tubulin genes (CameTUB1..CameTUB9).

Therefore, the cTBP marker and Southern hybridization analysis have highlighted a high variability among the different species which could be exploited to improve the genetic background of the cultivated species with respect to its utilization as a biofuel crop.

In addition to its discrimination power at plant species level, the cTBP method can also provide information on the ploidy status of a plant species. Breviario et al. [23] reported that the number of amplified bands in the genus Eleusine strongly correlates with the ploidy level of each taxon. Indeed, the three tetraploids E. coracana ssp. coracana, E. coracana ssp. africana, and E. kigeziensis show a consistently higher number of cTBP bands than that produced from each Eleusine diploid species. Similarly, the high number of cTBP bands detected in $C$. sativa, C. microcarpa and C. alyssum is fully consistent with their hexaploid status [19] [20]. Our results on $C$. rumelica, characterized by a chromosome number $2 n=26$ and a reduced number of cTBP bands compared to $C$. sativa, C. microcarpa and C. alyssum, suggest a tetraploid status for this species. Finally, a diploid chromosomal status is suggested for $C$. hispida, C. laxa and Camelina spp. in view of the low number of the cTBP amplified bands and the small number of chromosomes ( $2 \mathrm{n}=14 \mathrm{C}$ hispida; $2 \mathrm{n}=12$ C laxa and $2 \mathrm{n}=12$ Camelina spp.), relative to that of $C$. sativa, C. alyssum and C. microcarpa $(2 \mathrm{n}=40)$ [14] [29].

The phylogenetic tree emerging from the analysis of the isolated $\beta$-tubulin genes demonstrate a distribution of 
the different camelina $\beta$-tubulin isotypes that is spread throughout the clusters without separation from the $A$. thaliana orthologs. A similar distribution was reported in other studies that compared several $\beta$-tubulin genes of monocotyledonous and dicotyledonous plants [30]-[32]. Thus, our results provide further evidence that the angiosperm $\beta$-tubulin genes have likely originated from a single ancestral gene and that the only group of the tree (group C2), which does not include any $\beta$-tubulin counterpart from $A$. thaliana, might actually have originated by a duplication and a speciation event that took place after the separation of the two species. With regard to the lack of members of $C$. hispida and C. microcarpa in the B1 group this has most likely to be attributed to failure in cloning large size sequences.

\section{Conclusion}

In this study, we have shown that the cTBP molecular marker may indeed be a useful tool for the correct classification of Camelina germplasm species and, more generally, for unequivocal identification of any other plant species and accessions. In addition, cTBP might be very useful to track interspecies introgression events that may result from breeding programs aimed to widen the genetic base of the cultivated $C$. sativa.

\section{Acknowledgements}

This work was partially supported by Regione Lombardia, Agreement Regione Lombardia/Cnr, Project 2 "Risorse biologiche e tecnologie innovative per lo sviluppo sostenibile del sistema agro-alimentare”.

\section{References}

[1] Warwick, S.I., Francis, A. and Al-Shehbaz, I.A. (2006) Brassicaceae: Species Checklist and Database on CD Rom. Plant Systematic and Evolution, 259, 249-258. http://dx.doi.org/10.1007/s00606-006-0422-0

[2] Bernardo, A., Howard-Hildige, R., O’Connell, A., Ryan, J., Rice, B., Roche, E. and Leahy, J.J. (2003) Camelina Oil as a Fuel for Diesel Transport Engines. Industrial Crops and Products, 17, 191-197. http://dx.doi.org/10.1016/S0926-6690(02)00098-5

[3] Fröhlich, A. and Rice, B. (2005) Evaluation of Camelina sativa Oil as a Feedstock for Biodiesel Production. Industrial Crops and Products, 21, 25-31. http://dx.doi.org/10.1016/j.indcrop.2003.12.004

[4] Soriano, N.U. and Narami, A. (2012) Evaluation of Biodiesel Derived from Camelina sativa Oil. Journal of the American Oil Chemists' Society, 89, 917-923. http://dx.doi.org/10.1007/s11746-011-1970-1

[5] Zaleckas, E., Makarevičienè, V. and Sendžikienė, E. (2012) Possibilities of Using Camelina sativa Oil for Producing Biodiesel Fuel. Transport, 27, 60-66. http://dx.doi.org/10.3846/16484142.2012.664827

[6] Shonnard, D.R., Williams, L. and Kalnes, T.N. (2010) Camelina-Derived Jet Fuel and Diesel: Sustainable Advanced Biofuels. Environmental Progress \& Sustainable Energy, 3, 382-392. http://dx.doi.org/10.1002/ep.10461

[7] Agusdinata, D.B., Zhao, F., Ileleji, K. and De Laurentis, D. (2011) Life Cycle Assessment of Potential Biojet Fuel Production in the United States. Environmental Science \& Technology, 45, 9133-9143. http://dx.doi.org/10.1021/es202148g

[8] Zubr, J. (1997) Oil-Seed Crop: Camelina sativa. Industrial Crops and Products, 6, 113-119. http://dx.doi.org/10.1016/S0926-6690(96)00203-8

[9] Rode, J. (2002) Study of autochthon Camelinasativa (L.) Crantz in Slovenia. Journal of Herbs, Spices \& Medicinal Plants, 9, 313-318. http://dx.doi.org/10.1300/J044v09n04 08

[10] Budin, J.T., Breene, W.M. and Putnam, D.H. (1995) Some Compositional Properties of Camelina (Camelina sativa (L.) Crantz) Seeds and Oils. Journal of the American Oil Chemists' Society, 72, 309-315. http://dx.doi.org/10.1007/BF02541088

[11] Zubr, J. and Matthäus, B. (2002) Effects of Growth Conditions on Fatty Acids and Tocopherols in Camelina sativa Oil. Industrial Crops and Products, 15, 155-162. http://dx.doi.org/10.1016/S0926-6690(01)00106-6

[12] Abramovic, H., Butinar, B. and Nikolič, V. (2007) Changes Occurring in Phenolic Content, Tocopherol Composition and Oxidative Stability of Camelina sativa Oil during Storage. Food Chemistry, 104, 903-909. http://dx.doi.org/10.1016/j.foodchem.2006.12.044

[13] Hrastar, R., Abramovič, H. and Košir, I.J. (2012) In Situ Quality Evaluation of Camelina sativa Landrace. European Journal of Lipid Science and Technology, 114, 343-351. http://dx.doi.org/10.1002/ejlt.201100003

[14] Gehringer, A., Friedt, W., Lühs, W. and Snowdon, R.J. (2006) Genetic Mapping of Agronomic Traits in False Flax (Camelina sativa Subsp. sativa). Genome, 49, 1555-1563. http://dx.doi.org/10.1139/g06-117 
[15] Vollmann, J., Grausgruber, H., Stift, G., Dryzhyruk, V. and Lelley, T. (2005) Genetic Diversity in Camelina germplasm as Revealed by Seed Quality Characteristics and RAPD Polymorphism. Plant Breeding, 124, 446-453. http://dx.doi.org/10.1111/j.1439-0523.2005.01134.x

[16] Ghamkhar, K., Croser, J., Aryamanesh, N., Campbell, M., Kon’kova, N. and Francis, C. (2010) Camelina (Camelina sativa (L.) Crantz) as an Alternative Oilseed: Molecular and Ecogeographic Analyses. Genome, 53, 558-567. http://dx.doi.org/10.1139/G10-034

[17] Galasso, I., Manca, A., Braglia, L., Martinelli, T., Morello, L. and Breviario, D. (2011) h-TBP: An Approach Based on Intron-Length Polymorphism for the Rapid Isolation and Characterization of the Multiple Members of the $\beta$-Tubulin Gene Family in Camelina sativa (L.) Crantz. Molecular Breeding, 28, 635-645. http://dx.doi.org/10.1007/s11032-010-9515-0

[18] Manca, A., Pecchia, P., Mapelli, S., Masella, P. and Galasso, I. (2012) Evaluation of Genetic Diversity in a Camelina sativa (L.) Crantz Collection Using Microsatellite Markers and Biochemical Traits. Genetic Resources and Crop Evolution, 60, 1223-1236. http://dx.doi.org/10.1007/s10722-012-9913-8

[19] Hutcheon, C., Ditt, R.F., Beilstein, M., Comai, L., Schroeder, J., Goldstein, E., Shewmaker, C.K., Nguyen, T., De Rocher, J. and Kiser, J. (2010) Polyploid Genome of Camelina sativa Revealed by Isolation of Fatty Acid Synthesis Genes. BMC Plant Biology, 10, 233. http://dx.doi.org/10.1186/1471-2229-10-233

[20] Kagale, S., Koh, C., Nixon, J., Bollina, V., Clarke, W.E., Tuteja, R., Spillane, C., Robinson, S.J., Links, M.G., Clarke, C., Higgins, E.E., Huebert, T., Sharpe, A.G. and Parkin, I.A. (2014) The Emerging Biofuel Crop Camelina sativa Retains a Highly Undifferentiated Hexaploid Genome Structure. Nature Communications, 5, Article ID: 3706. http://dx.doi.org/10.1038/ncomms4706

[21] Plessers, A.G., McGregor, W.G., Carson, R.B. and Nakoneshny, W. (1962) Species Trials with Oilseed Plants: II. Camelina. Canadian Journal of Plant Science, 42, 452-459. http://dx.doi.org/10.4141/cjps62-073

[22] Bardini, M., Lee, D., Donini, P., Mariani, A., Gianì, S., Toschi, M., Lowe, C. and Breviario, D. (2004) Tubulin-Based Polymorphism (TBP): A New Tool, Based on Functionally Relevant Sequences, to Assess Genetic Diversity in Plant Species. Genome, 47, 281-291. http://dx.doi.org/10.1139/g03-132

[23] Breviario, D., Vance Baird, W., Sangoi, S., Hilu, K., Blumetti, P. and Gianì, S. (2007) High Polymorphism and Resolution in Targeted Fingerprinting with Combined $\beta$-Tubulin Introns. Molecular Breeding, 20, 249-259. http://dx.doi.org/10.1007/s11032-007-9087-9

[24] Braglia, L., Manca, A., Mastromauro, F. and Breviario, D. (2010) cTBP: A Successful ILP-Based Genotyping Method Targeted to Well Defined Experimental Needs. Diversity, 2, 572-585. http://dx.doi.org/10.3390/d2040572

[25] Poczai, P., Varga, I., Laos, M., Cseh, A., Bell, N., Valkonen, J.P.T. and Hyvönen, J. (2013). Advances in Plant Gene Targeted and Functional Markers: A Review. Plant Methods, 9, 6. http://dx.doi.org/10.1186/1746-4811-9-6

[26] Tamura, K., Peterson, D., Peterson, N., Stecher, G., Nei, M. and Kuma, S. (2011) MEGA5: Molecular Evolutionary Genetics Analysis Using Maximum Likelihood, Evolutionary Distance, and Maximum Parsimony Methods. Molecular Biology and Evolution, 28, 2731-2739. http://dx.doi.org/10.1093/molbev/msr121

[27] Doyle, J.J. and Doyle, J.L. (1987) A Rapid DNA Isolation Procedure for Small Quantities of Fresh Leaf Tissue. Phytochemical Bulletin, 19, 11-15.

[28] Schwarzacher, T. and Heslop-Harrison, J.S. (2000) Practical in Situ Hybridization. BIOS Scientific Publishers, Oxford, 203.

[29] Francis, A. and Warwick, S.I. (2009) The Biology of Canadian Weeds. 142. Camelina alyssum (Mill.) Thell.; C. microcarpa Andrz. ex DC.; C. sativa (L.) Crantz. Canadian Journal of Plant Science, 89, 791-810. http://dx.doi.org/10.4141/CJPS08185

[30] Jost, W., Baur, A., Nick, P., Reski, R. and Gorr, G. (2004) A Large Plant $\beta$-Tubulin Family with Minimal C-Terminal Variation but Differences in Expression. Gene, 340, 151-160. http://dx.doi.org/10.1016/j.gene.2004.06.009

[31] Oakley, R.V., Wang, Y.S., Ramakrishna, W., Harding, S.A. and Tsai, C.J. (2007) Differential Expansion and Expression of $\alpha$ - and $\beta$-Tubulin Gene Families in Populus. Plant Physiology, 145, 961-973. http://dx.doi.org/10.1104/pp.107.107086

[32] Breviario, D., Gianì, S. and Morello, L. (2013) Multiple Tubulins: Evolutionary Aspects and Biological Implications. Plant Journal, 75, 202-218. http://dx.doi.org/10.1111/tpj.12243 
ESM-Table 1. $\beta$-tubulin isotypes isolated from Camelina species. For each isotype is reported the EMBL accession number, the complete size in base pair (bp), the length of intron1 (Int1) and intron2 (Int2). Microsatellites and tandem repeats present in the Int1 and/or Int2 are reported. Numbers in the tandem repeats column indicated the position of the repeat motif in the nucleotide sequence. Dash (-) is introduced for better alignment.

\begin{tabular}{|c|c|c|c|c|c|c|}
\hline $\begin{array}{l}\text { C. rumelica } \\
\text { CAM244 }\end{array}$ & $\begin{array}{l}\text { Size } \\
\text { bp }\end{array}$ & $\begin{array}{c}\text { Int1 } \\
\text { bp }\end{array}$ & $\begin{array}{l}\text { Int2 } \\
\text { bp }\end{array}$ & Microsatellites & Tandem Repeats & $\begin{array}{l}\text { EMBL } \\
\text { Accession } \\
\text { Number }\end{array}$ \\
\hline CrTUB1 & 693 & 87 & 92 & & & LN811270 \\
\hline CrTUB2 & 713 & 107 & 92 & & & LN811271 \\
\hline CrTUB3 & 730 & 119 & 97 & & & LN811272 \\
\hline CrTUB4 & 731 & 119 & 98 & & & LN811273 \\
\hline CrTUB5 & 781 & 163 & 104 & & & LN811274 \\
\hline CrTUB6 & 782 & 166 & 103 & & & LN811275 \\
\hline CrTUB7 & 793 & 100 & 179 & & & LN811276 \\
\hline CrTUB8 & 803 & 191 & 98 & & & LN811277 \\
\hline CrTUB9 & 864 & 106 & 244 & $\operatorname{Int1}(\mathrm{CTT})_{7}$ & & LN811278 \\
\hline CrTUB10 & 1120 & 111 & 578 & & $\begin{array}{l}\text { Int2 } \\
707 \text { 5’TGCTATTCTCTCTTGTTAAG 3’726 } \\
727 \text { 5’TGCTATACTTTCTTGTTAAG 3’746 }\end{array}$ & LN811279 \\
\hline CrTUB11 & 1122 & 210 & 115 & & $\begin{array}{l}\text { Int1 } \\
193 \\
\text { 5’TCTGATTT-GAACTGGTAATT-GCGGATTAAGTTGCTTATG } \\
\text { GTGGTT 3'237 } \\
\text { 238 } \\
\text { 5'TCTGATTTTGAACTGGTATTTTGGGGATTAGGTTGCTTATG } \\
\text { GTGGTT 3'284 }\end{array}$ & LN811280 \\
\hline CrTUB12 & 1154 & 171 & 469 & & & LN811281 \\
\hline CrTUB13 & 1298 & 206 & 92 & & $\begin{array}{l}\text { Int1 } \\
200 \\
\text { 5'ATTTTGAACTGGTAATTGCGGATTAGTTTGCTTATGGTC } \\
\text { 3’238 } \\
\text { 239 } \\
\text { 5'ATTTTGAACTGGTAATTGCGGATTAGGTTGCTTATGGTG } \\
\text { 3'276 }\end{array}$ & LN811282 \\
\hline CrTUB14 & 1324 & 718 & 495 & & & LN811283 \\
\hline CrTUB15 & 1497 & 868 & 398 & & & LN811284 \\
\hline \multicolumn{7}{|l|}{$\begin{array}{l}\text { C. microcarpa } \\
\text { CAM47 }\end{array}$} \\
\hline CmTUB1 & 694 & 88 & 92 & & & LN811285 \\
\hline CmTUB2 & 704 & 99 & 92 & Int2(TA) $)_{5}$ & & LN811286 \\
\hline CmTUB3 & 723 & 115 & 94 & $\operatorname{Int} 2(\mathrm{TA})_{5}$ & & LN811287 \\
\hline CmTUB4 & 758 & 148 & 96 & & & LN811288 \\
\hline CmTUB5 & 765 & 152 & 99 & & & LN811289 \\
\hline CmTUB6 & 767 & 144 & 109 & & & LN811290 \\
\hline CmTUB7 & 797 & 104 & 179 & & & LN811291 \\
\hline
\end{tabular}




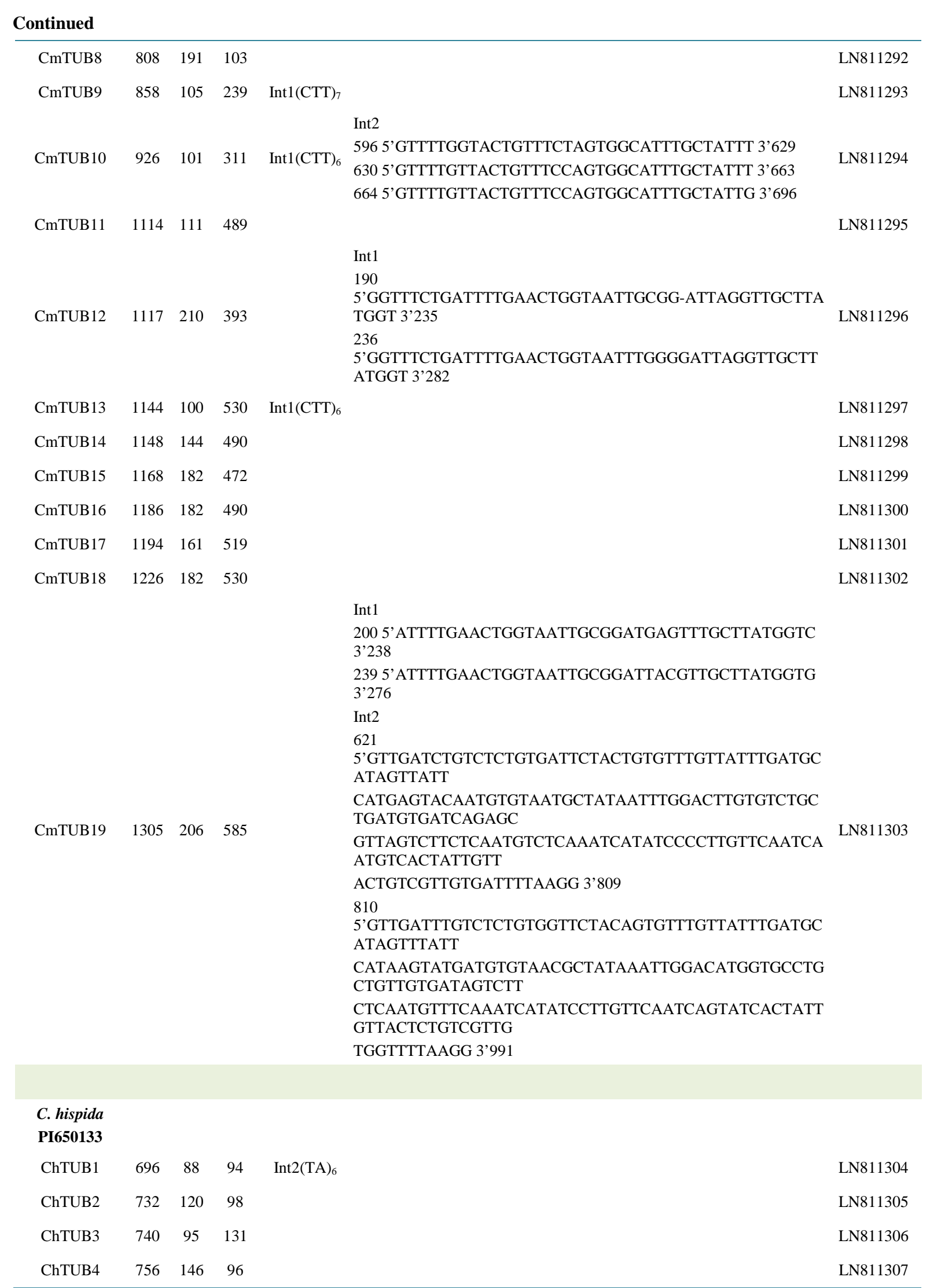




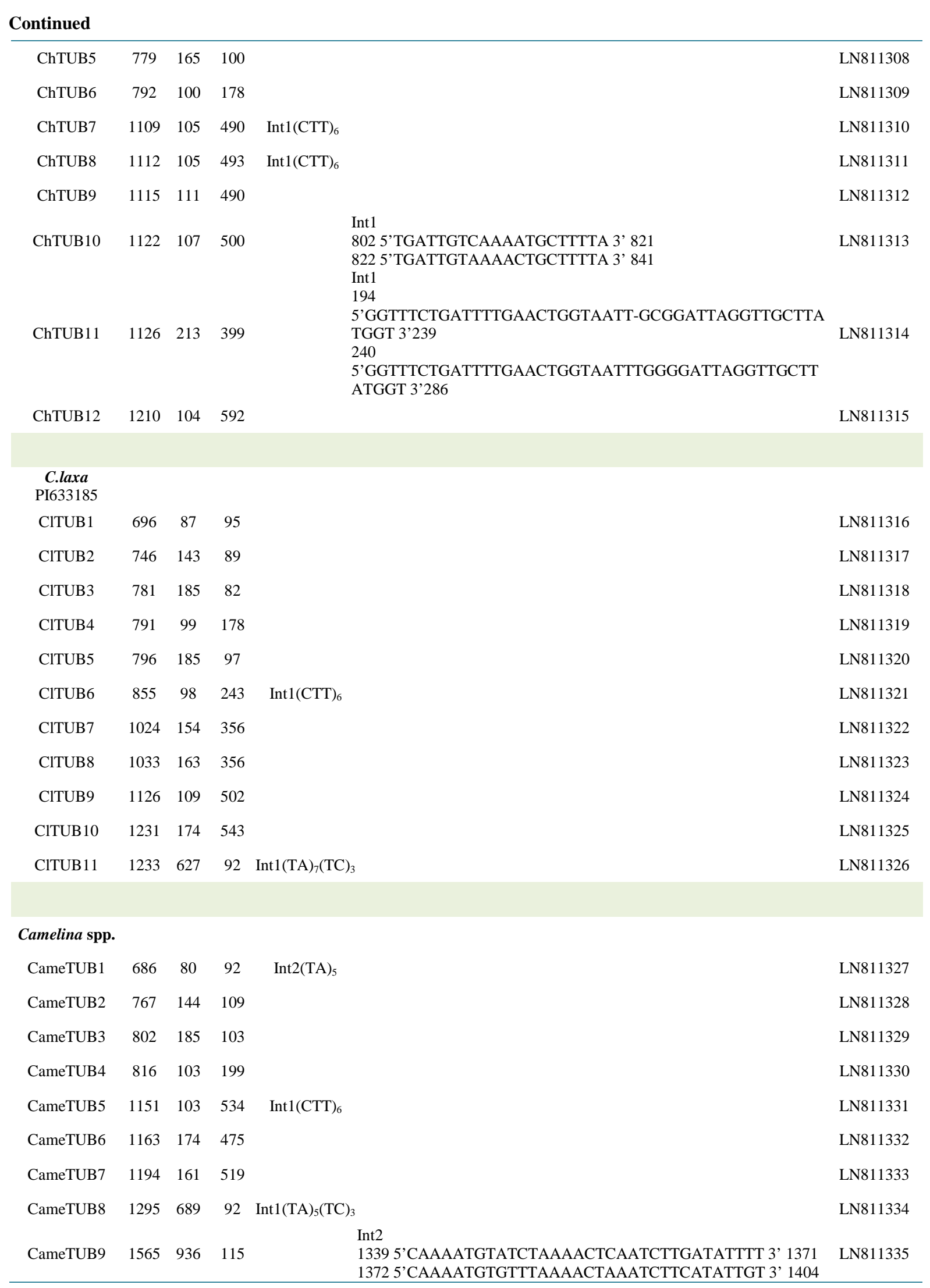

